\title{
Editorial NPL 1/2021
}

\author{
Jens Ivo Engels • Volker Köhler
}

Angenommen: 13. Januar 2021 / Online publiziert: 28. Januar 2021

(C) Der/die Autor(en) 2021

\section{Liebe Leserinnen und Leser,}

wir hoffen sehr, dass Sie gut und gesund durch die bisherigen Monate gekommen sind. Seit fast einem Jahr leben und arbeiten wir nun unter den Bedingungen einer Pandemie. Während wir diese Zeilen schreiben, ist weiterhin unklar, wie lange die Pandemie unseren Alltag und unsere Arbeit beherrschen wird.

$\mathrm{Zu}$ Beginn des neuen Jahrgangs wenden wir uns an Sie, weil die Einschränkungen der letzten Monate nun auch ihren Niederschlag in der NPL finden werden. Ähnlich wie wahrscheinlich bei den meisten von Ihnen hat sich unser redaktioneller Arbeitsalltag im vergangenen Jahr drastisch verändert. Seit März arbeiten wir im HomeOffice. Wir sind mittlerweile gut in dieser neuen, digitalen Welt angekommen. Vor allem sind wir froh und dankbar, dass auch unsere Autorenschaft den Übergang in die Corona-Arbeitswelt gut gemeistert hat. Das war und ist nicht selbstverständlich. Viele von uns waren mit geschlossenen Schulen und Kindertagesstätten, begrenzt zugänglichen Bibliotheken und Archiven und vielen anderen Nöten der Pandemie konfrontiert.

Es machen sich nun die Folgen der Pandemie bemerkbar. Frühjahr und Sommer 2020 waren eine Zeit, in der weniger Beiträge als üblich bei uns eingingen. AuBerdem benötigte die Redaktion eine gewisse Umstellungszeit. Das hatte wegen der Vorlaufzeiten im Jahrgang 2020 noch kaum Konsequenzen. Im laufenden Jahr ist aber zu erwarten, dass die NPL an der einen oder anderen Stelle etwas dünner als gewohnt ausfällt und stärker als üblich auf Essays setzt.

J. I. Engels · V. Köhler (ه)

Technische Universität Darmstadt, Darmstadt, Deutschland

E-Mail: npl-redaktionsleitung@pg.tu-darmstadt.de 
Dies ändert nichts an unserem Qualitätsanspruch: Wir sind uns sicher, Ihnen auch in diesem Jahr interessante und spannende Texte präsentieren zu dürfen. Dafür sorgen unsere hervorragenden Autorinnen und Autoren.

In diesem Sinne wünschen wir Ihnen alles Gute, vor allem Gesundheit für das Jahr 2021.

\section{Mit besten Grüßen aus Darmstadt \\ Jens Ivo Engels \\ Volker Köhler}

Funding Open Access funding enabled and organized by Projekt DEAL.

Open Access Dieser Artikel wird unter der Creative Commons Namensnennung 4.0 International Lizenz veröffentlicht, welche die Nutzung, Vervielfältigung, Bearbeitung, Verbreitung und Wiedergabe in jeglichem Medium und Format erlaubt, sofern Sie den/die ursprünglichen Autor(en) und die Quelle ordnungsgemäß nennen, einen Link zur Creative Commons Lizenz beifügen und angeben, ob Änderungen vorgenommen wurden.

Die in diesem Artikel enthaltenen Bilder und sonstiges Drittmaterial unterliegen ebenfalls der genannten Creative Commons Lizenz, sofern sich aus der Abbildungslegende nichts anderes ergibt. Sofern das betreffende Material nicht unter der genannten Creative Commons Lizenz steht und die betreffende Handlung nicht nach gesetzlichen Vorschriften erlaubt ist, ist für die oben aufgeführten Weiterverwendungen des Materials die Einwilligung des jeweiligen Rechteinhabers einzuholen.

Weitere Details zur Lizenz entnehmen Sie bitte der Lizenzinformation auf http://creativecommons.org/ licenses/by/4.0/deed.de. 